\title{
Effect of Estragole on Leukocyte Behavior and Phagocytic Activity of Macrophages
}

\author{
Francielli Maria de Souza Silva-Comar, ${ }^{1}$ Luiz Alexandre Marques Wiirzler, ${ }^{1}$ \\ Saulo Euclides Silva-Filho, ${ }^{1}$ Raquel Kummer, ${ }^{1}$ Raissa Bocchi Pedroso, ${ }^{2}$ \\ Ricardo Alexandre Spironello, ${ }^{1}$ Expedito Leite Silva, ${ }^{3}$ \\ Ciomar Aparecida Bersani-Amado, ${ }^{1}$ and Roberto Kenji Nakamura Cuman ${ }^{1}$ \\ ${ }^{1}$ Department of Pharmacology and Therapeutics, State University of Maringá, Avenida Colombo 5790, \\ 870020-900 Maringá, PR, Brazil \\ ${ }^{2}$ Department of Clinical Analyses, State University of Maringá, 870020-900 Maringá, PR, Brazil \\ ${ }^{3}$ Department of Chemistry, State University of Maringá, 870020-900 Maringá, PR, Brazil \\ Correspondence should be addressed to Francielli Maria de Souza Silva-Comar; franciellimss@gmail.com
}

Received 24 April 2014; Revised 6 June 2014; Accepted 21 June 2014; Published 23 July 2014

Academic Editor: Yew-Min Tzeng

Copyright ( $) 2014$ Francielli Maria de Souza Silva-Comar et al. This is an open access article distributed under the Creative Commons Attribution License, which permits unrestricted use, distribution, and reproduction in any medium, provided the original work is properly cited.

\begin{abstract}
Estragole, a chemical constituent of the essential oils of many aromatic plants, is used as flavoring in beverage and food industries. In vivo and in vitro experimental assays have shown that EST has sedative, anticonvulsant, antioxidant, antimicrobial, and anesthetic activity. In this work, we evaluate the effect of EST on leukocyte behavior and phagocytic activity of macrophages. In the peritonitis model, EST $(500$ and $750 \mathrm{mg} / \mathrm{kg}$ ) decreased the infiltration of peritoneal exudate leukocytes. In vitro chemotaxis assay showed that $\operatorname{EST}(3,10,30$, and $60 \mu \mathrm{g} / \mathrm{mL})$ inhibited neutrophil migration toward fMLP. In the in vivo microcirculation assay, EST at doses of 250,500 , and $750 \mathrm{mg} / \mathrm{kg}$ significantly reduced the number of rolling and adherent leukocytes and at doses of 250 and $500 \mathrm{mg} / \mathrm{kg}$ decreased number of leukocyte migrated to perivascular tissue. The results showed that EST $(3,10$, and $30 \mu \mathrm{g} / \mathrm{mL})$ was able to stimulate the macrophages phagocytosis but only at concentration of $10 \mu \mathrm{g} / \mathrm{mL}$ promoted an increase in nitric oxide (NO) production. In conclusion, this study showed that EST had potential anti-inflammatory effects, likely by inhibiting leukocyte migration and by stimulating macrophages phagocytosis.
\end{abstract}

\section{Introduction}

Estragole (EST) is a monoterpene that is largely used in the food and beverage industry as a flavoring and also in the perfumes, soap, and detergents. It is an important chemical constituent of the essential oils of many aromatic plants, such as Croton zehntneri Pax et Hoffm., Artemisia dracunculus (Asteraceae), Ocimum basilicum (Lamiaceae), Pimpinella anisum (Apiaceae), Illicium anisatum (Illiciaceae), and Foeniculum vulgare (Apiaceae) $[1,2]$.

In vivo and in vitro experimental assays have shown that EST has sedative, anticonvulsant, antimicrobial, and antioxidant activities, affects central nervous system, and acts as nervous excitability blocker in a concentration-dependent manner and in neuronal excitability by direct inhibition of $\mathrm{Na}^{+}$channels [3-6]. Anethole, a position isomer of EST, showed anti-inflammatory properties as demonstrated in carrageenan-induced pleurisy in rats, inhibited TNF-induced inflammation, and reduced the inflammatory pain in models of carrageenan-induced paw edema and mechanical hypernociception [7-9]. Although several studies have demonstrated the effects of EST, there are few reports in the literature of the anti-inflammatory activity of this compound. Only its antiedematogenic effect on acute paw edema in mice was demonstrated [10].

The acute inflammation is a process characterized by a vascular response and initial recruitment of polymorphonuclear cells, typically neutrophils, followed by monocytes, 
which differentiate into macrophages. Neutrophils, via expression of adhesion molecules, adhere to the endothelium and migrate to reach the site of injury $[11,12]$. The inflammatory reaction is necessary for tissue recovery and provides the correct cytokine signals and cell machinery to clear up the site for tissue regeneration. However, uncontrolled inflammation accompanied by the excessive migration of leukocytes has unfavorable effects on the course of tissue healing due to proteolytic enzymes release and reactive oxygen species production [13].

The present study was performed to evaluate the antiinflammatory activity of EST in different models of acute inflammation. Specifically it has measured the carrageenaninduced peritonitis in mice, in vivo leukocyte migration in rats, in vitro chemotaxis, cytotoxicity, and phagocytic activity assay.

\section{Materials and Methods}

2.1. Chemicals. Estragole, indomethacin, zymosan, LPS (lipopolysaccharides from Salmonella enterica serotype typhimurium), fMLP (formyl-methionyl-leucyl-phenylalanine), and carrageenan were purchased from Aldrich Chemical Co.

2.2. Animals. Male Wistar rats (180-220 g) and male mice BALB-c (20-25 g) were maintained under a controlled temperature of $22^{\circ} \mathrm{C}$ on a $12 \mathrm{~h}$ light/dark cicle and receiving food and water ad libitum. The experimental protocols were approved by the Ethical Committee in Animal Experimentation of the State University of Maringá (CEAE/UEM 126/2010).

2.3. Peritonitis Model. BALB-c mice, in groups of five animals to each dose, were orally treated with EST (250, 500, or $750 \mathrm{mg} / \mathrm{kg}$ ) $30 \mathrm{~min}$ before the intraperitoneal injection carrageenan solution $(500 \mu \mathrm{g} / \mathrm{mice})$. The animals were euthanized $4 \mathrm{~h}$ later and the peritoneal cavity was washed with $2 \mathrm{~mL}$ of phosphate-buffered saline (PBS) that contained ethylenediaminetetraacetic acid (EDTA). The leukocyte count was determined in the fluid recovered from the peritoneal cavity. The results obtained in the differential count were expressed as the number of neutrophils per cavity.

2.4. In Vivo Leukocyte Migration. Rolling and adhesion of leukocytes to the endothelium were evaluated in the rat internal spermatic fascia $2 \mathrm{~h}$ after carrageenan injection $(100 \mu \mathrm{g})$ in the wall of the scrotal chamber. EST $(250,500$, or $750 \mathrm{mg} / \mathrm{kg}$ ), indomethacin $(5 \mathrm{mg} / \mathrm{kg})$, or saline $(0.9 \%)$ was administered orally $30 \mathrm{~min}$ before carrageenan injection to different groups of rats ( $n=5-7$ animals/group). Animals anesthetized with chloral hydrate $(600 \mathrm{mg} / \mathrm{kg}$, s.c.) were maintained on a special board thermostatically controlled at $37^{\circ} \mathrm{C}$ with a transparent platform for transillumination of the tissue on which the spermatic fascia was exposed and fixed for analysis by microscopy in situ. The preparation was kept moist and warm with Ringer-Locke's solution ( $\mathrm{pH} 7.2-$ 7.4) containing $1 \%$ gelatin. The vessels selected for the study were postcapillary venules with a diameter of $15-25 \mu \mathrm{m}$. The number of rolling and adherent leukocytes was determined at $10 \mathrm{~min}$ intervals. The leukocytes were considered to adhere to the venular endothelium if they remained stationary for more than $30 \mathrm{~s}$. In another series of experiments, the number of leukocytes that migrated to an area of $2,500 \mu \mathrm{m}^{2}$ of connective tissue adjacent to postcapillary venules $4 \mathrm{~h}$ after carrageenan injection was determined. The number of cells was determined by an image recorded using four different fields for each animal, and the average value was calculated.

2.5. Chemotaxis Assay. To evaluate the effects of EST on chemotaxis, neutrophils were obtained 4 hours after injection of solution of zymosan in saline $(1 \mathrm{mg} /$ cavity) into the peritoneal cavity of BALB-c mice. The cell number was adjusted to $1 \times 10^{6}$ cells $/ \mathrm{mL}$ in RPMI medium that contained $0.1 \%$ bovine serum albumin (BSA). The chemotaxis assay was performed using a 48-well microchemotaxis plate (Neuro Probe), in which the chambers were separated by a polyvinylpyrrolidone-free polycarbonate membrane $(5 \mu \mathrm{m}$ pore size). The chemoattractant $N$-formyl methionyl leucyl phenylalanine (fMLP; $10^{-6} \mathrm{M}$ ) and a negative control (RPMI 1640) were placed in the lower chamber. A neutrophil suspension $\left(1 \times 10^{6}\right.$ cells $\left./ \mathrm{mL}\right)$ pretreated with $\operatorname{EST}(3,10,30$, or $60 \mu \mathrm{g} / \mathrm{mL}$ ) for $30 \mathrm{~min}$ was then placed in the upper chamber. The cells were allowed to migrate into the membrane for $1 \mathrm{~h}$ at $37^{\circ} \mathrm{C}$ in $5 \% \mathrm{CO}_{2}$. After incubation period, the membrane was washed and stained using Instant Prov (Newprove). The membrane area of each well was scored using light microscopy to count the intact cells present in five random fields. The results were expressed as the mean number of neutrophils per field and representative of three separate experiments.

2.6. Phagocytic Assay. Peritoneal macrophages from male BALB-c mice (20-25 g) were collected with precooled phosphate buffer saline (PBS), harvested in RPMI 1640 medium pH 7.6 supplemented with $10 \%$ FBS $\left(5 \times 10^{5}\right.$ cells $\left./ \mathrm{mL}\right)$, and plated on $13 \mathrm{~mm}$ coverslips in 24-well culture plates for $1 \mathrm{~h}$ at $37^{\circ} \mathrm{C}$ in a $5 \% \mathrm{CO}_{2}$ atmosphere. Nonadherent cells were then removed and adhered to macrophages cultured with EST (3, 10,30 , or $60 \mu \mathrm{g} / \mathrm{mL}$ ) in RPMI 1640 medium supplemented with $10 \% \mathrm{FBS}$ for $24 \mathrm{~h}$ at $37^{\circ} \mathrm{C}$ in a $5 \% \mathrm{CO}_{2}$. After this, treated macrophages were challenged with multiples of 10 chicken red blood cells (CRBC) for each macrophage and incubated for $1 \mathrm{~h}$ at $37^{\circ} \mathrm{C}$ in a $5 \% \mathrm{CO}_{2}$ atmosphere. The monolayers were fixed with xylol and stained with panótico. The number of phagocytized CRBC was determined by counting at least 100 macrophages in duplicate cultures, and results were expressed as the phagocytosis index (PI), the percentage of infected macrophages by the mean number of phagocytized CRBC per cell. Cell viability was $\geq 90 \%$ in all experiments. LPS (lipopolysaccharide) at $20 \mu \mathrm{g} / \mathrm{mL}$ was used as positive control.

2.7. Measurement of Nitric Oxide (NO) in Macrophages. The level of NO production was monitored by measuring the nitrite level in the culture medium by Griess reaction. 


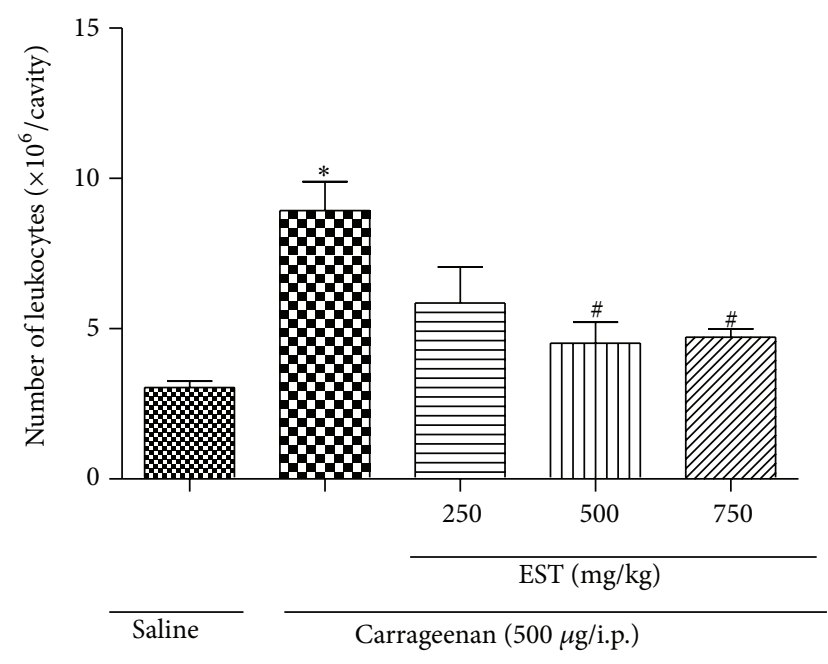

FIGURE 1: Effect of EST treatment on leukocyte number. Effect of treatments on leukocyte number 4 hours after carrageenan injection $(500 \mu \mathrm{g} /$ mice i.p.) in BALB-c mice. Values are mean \pm SEM $(n=$ 5). ${ }^{*} P<0.05$ versus saline (vehicle). ${ }^{*} P<0.05$ compared versus carrageenan group (one-way ANOVA, Tukey’s test).

Cell free supernatants $(50 \mu \mathrm{L})$ were incubated with equal volumes of Griess reagent mixtures (1\% sulfanilamide in $5 \%$ phosphoric acid and 0,1\% N-1-naphthylethylenediamine dihydrochloride in water) at room temperature for $10 \mathrm{~min}$. The absorbance was measured in a microplate reader at $550 \mathrm{~nm}$. NO concentrations were calculated from a sodium nitrite standard curve. Data were presented as $\mu \mathrm{M}$ concentration of $\mathrm{NO}^{2-}$.

2.8. Dimethylthiazol Diphenyltetrazolium Bromide (MTT) Assay. The tetrazolium reduction assay was done as described by Denizot and Lang [14]. Peritoneal macrophages were isolated as described above. The macrophages were incubated for $24 \mathrm{~h}$ with EST $(3 \mu \mathrm{g} / \mathrm{mL}, 10 \mu \mathrm{g} / \mathrm{mL}, 30 \mu \mathrm{g} / \mathrm{mL}$, or $60 \mu \mathrm{g} / \mathrm{mL}$ ). The supernatant was then removed and macrophages were incubated for $3 \mathrm{~h}$ with medium RMPI containing $5 \mathrm{mg}$ of $\mathrm{MTT} / \mathrm{mL}$. A hundred $\mu \mathrm{L}$ of DMSO was added in each well. The cells were incubated for $10 \mathrm{~min}$ at $25^{\circ} \mathrm{C}$. The resulting absorbance was measured at $540 \mathrm{~nm}$.

2.9. Statistical Analysis. Results are expressed as mean \pm standard error of the mean (SEM). Data were subjected to analysis of variance (ANOVA) followed by Tukey's post hoc test. Values of $P<0.05$ were considered statistically significant.

\section{Results and Discussion}

The acute inflammatory process is characterized by vasodilation, exudate formation, and leukocyte migration. The migration and accumulation of neutrophils at the inflammation site are crucial for host defense and these processes are mediated by a signaling cascade that involves adhesion molecules, several cytokines, and production of nitric oxide $[15,16]$.

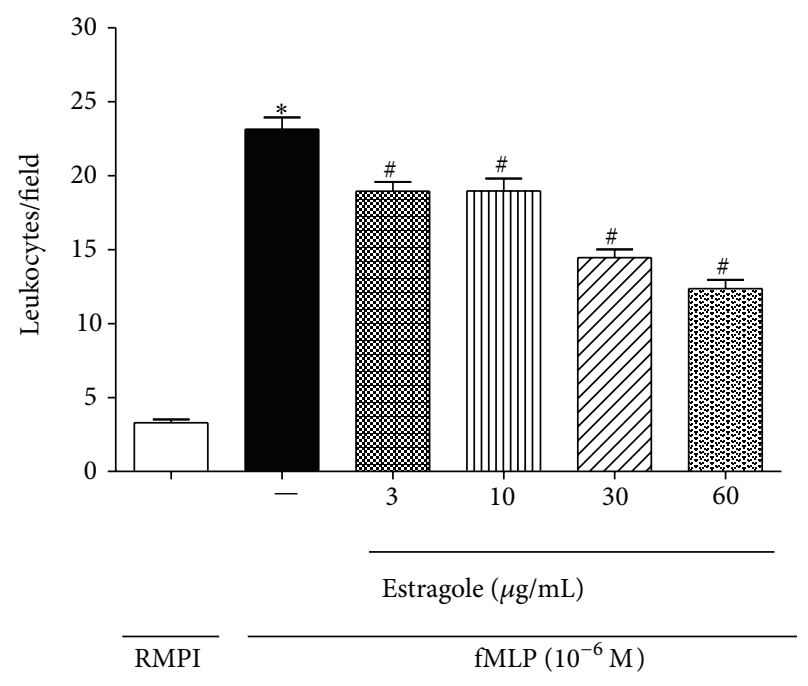

FIGURE 2: EST inhibited in vitro leukocyte chemotaxis. Leukocytes were obtained from zymosan-induced peritonitis ( $1 \mathrm{mg} /$ cavity) in mice and stimulated with fMLP $\left(10^{-6} \mathrm{M}\right)$ after $30 \mathrm{~min}$ of treatment with EST at doses 3, 10, 30, and $60 \mu \mathrm{g} / \mathrm{mL}$. Values are mean \pm SEM $(n=5)$ and are representative of three independent experiments. ${ }^{*} P<0.05$ versus medium (RPMI 1640); ${ }^{\#} P<0.05$ versus group of neutrophils stimulated with fMLP (one-way ANOVA, Tukey's test).

However, a persistent leukocyte migration may damage the surrounding tissue through the release of proteolytic enzymes and reactive metabolites of oxygen and nitrogen [17]. Thus, drugs that modulate leukocyte recruitment may provide an interesting therapeutic option for acute and chronic inflammation.

The inflammatory activity of EST was evaluated in a murine carrageenan-induced peritonitis model, used to screen anti-inflammatory drugs, and the results obtained are shown in Figure 1. Carrageenan is a phlogistic agent widely used for the induction of an inflammatory response involving the participation of cytokines (TNF- $\alpha$ and IL-1 $\beta$ ), arachidonic acid-derived mediators, and nitric oxide [18-20]. After $4 \mathrm{~h}$ of peritonitis induction, an inflammatory response was observed characterized by an increase in the number of leukocyte counts in the peritoneal cavity $\left(8.90 \pm 1.28 \times 10^{6}\right.$ cells/cavity) when compared with the control group (3.05 \pm $0.20 \times 10^{6}$ cells/cavity). The pretreatment of animals with EST at doses of 500 and $750 \mathrm{mg} / \mathrm{kg}$ significantly inhibited the leukocyte migration (51\% and 52\%, resp.), providing evidence that this compound presents activity on inflammation. There are some reports describing that monoterpene compounds, such as borneol, promote anti-inflammatory activity by reducing the leukocyte migration induced by carrageenan in peritonitis model [21]. Our data suggest that EST could have a similar effect on anethole, which was able to decrease leukocytes recruitment in carrageenan-induced pleurisy model, probably attributed to the inhibitory effect on production and/or release of nitric oxide and active metabolites of arachidonic acid [7].

To verify the direct effect of EST on in vitro leukocyte chemotaxis, the study was performed using $10^{-6} \mathrm{M}$ 


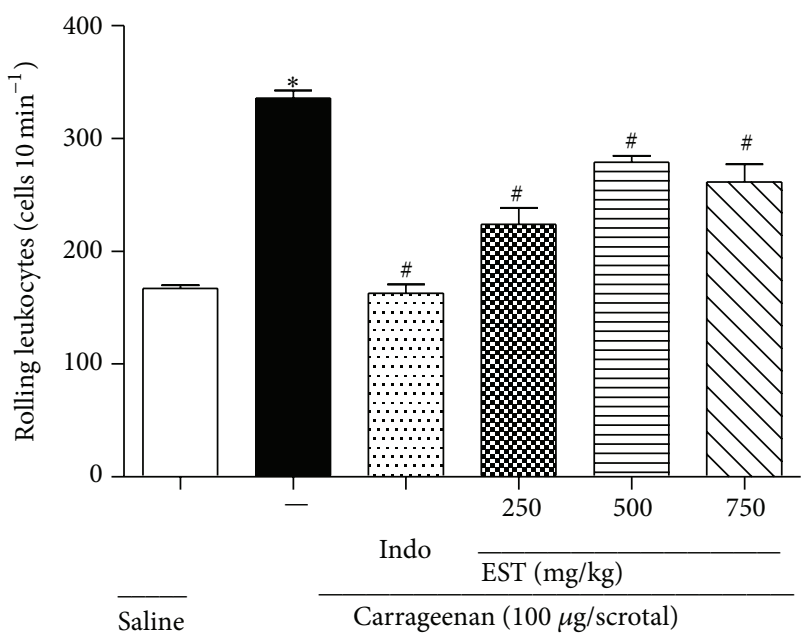

(a)

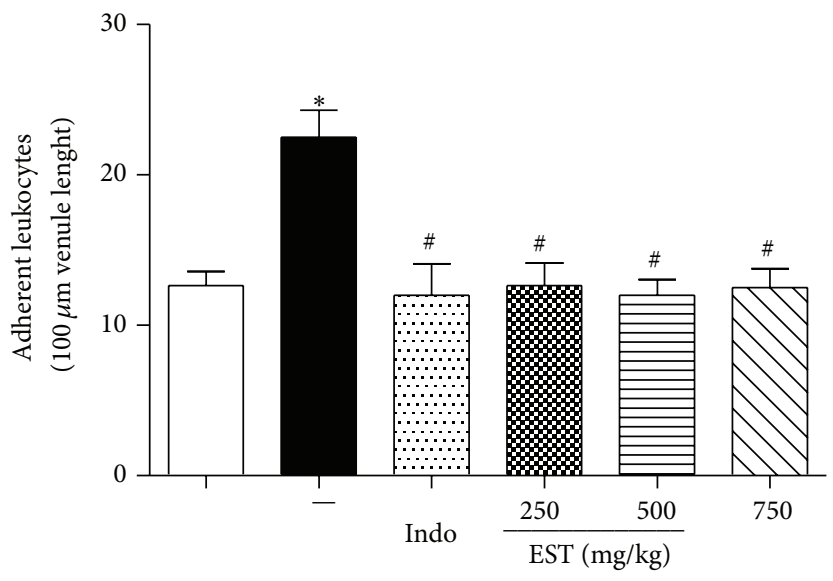

Saline
Carrageenan $(100 \mu \mathrm{g} / \mathrm{scrotal})$

(b)

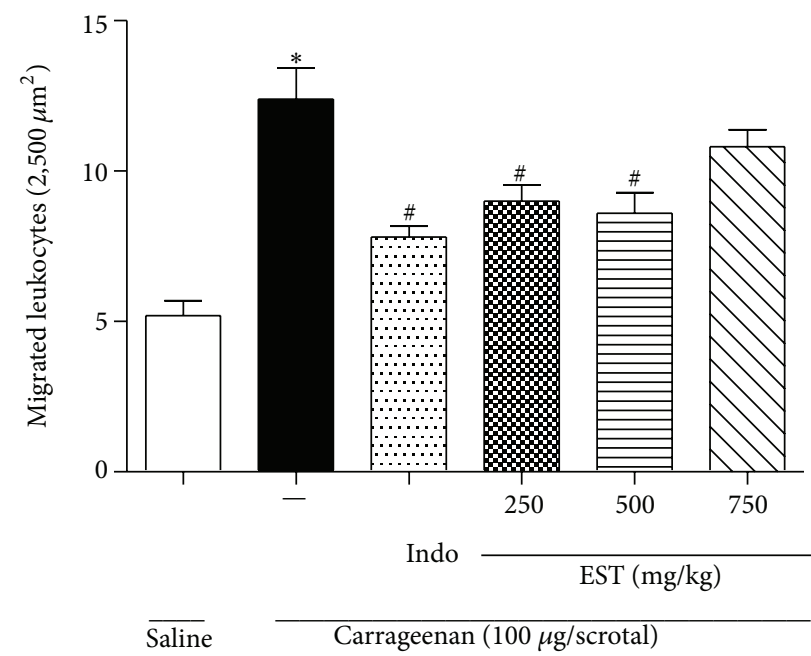

(c)

FIGURE 3: EST inhibited in vivo leukocyte migration in rats. The animals were orally treated with EST $(250,500$, or $750 \mathrm{mg} / \mathrm{kg})$ and indomethacin $(5.0 \mathrm{mg} / \mathrm{kg}) 30$ minutes before the injection of carrageenan (100 $\mu \mathrm{g} /$ scrotum). (a) Number of leukocytes rolling, (b) number of leukocytes adherent during 10-minute periods after $2 \mathrm{~h}$, and (c) leukocytes migrate after $4 \mathrm{~h}$ of inflammatory stimulus. Values represent mean \pm SEM ( $n=5-7$ animals/group) and are representative of three independent experiments. ${ }^{*} P<0.05$ versus vehicle; ${ }^{\#} P<0.05$ versus carrageenan-injected group (one-way ANOVA, Tukey's test).

fMLP (formyl-methionyl-leucyl-phenylalanine) as chemotactic agent. fMLP is a chemotactic agent associated with the production/release of cytokines, mainly IL- $1 \beta$, IL- 8 , and TNF- $\alpha$ [22]. The results obtained are shown in Figure 2. fMLP induced a significant leukocyte migration when compared with the control group (RPMI 1640). After leukocytes incubation with $\operatorname{EST}(3,10,30$, and $60 \mu \mathrm{g} / \mathrm{mL})$ a significant reduction $(18,10 \% ; 18,02 \% ; 37,55 \% ; 46,54 \%$, resp.; $P<0.05)$ in a dose-dependent manner of leukocyte migration in response to fMLP stimulation was observed. Since EST treatment did not affect the leukocytes viability evaluated by cytotoxicity assay at all concentrations tested (data not shown), our data suggest that the direct effect of EST on inhibition of leukocyte migration does not seem to be related to toxic effects (e.g., cell death). Recent study performed in our laboratory showed that both anethole and eugenol (structural analog of EST) reduced leukocyte migration induced by fMLP, probably by inhibitory effects of these compounds on synthesis/release cytokines [23].

Mechanisms by which the EST decreases the leukocyte migration to the inflammatory site were investigated using intravital microscopy system. EST was administered and the in vivo leukocyte-endothelial interactions (rolling, adhesion, and migration) were evaluated in the internal spermatic fascia postcapillary venules. During an inflammatory response, the leukocyte migration from the bloodstream to the site of injury occurs mainly in postcapillary venules by distinct events, such as rolling, adhesion, and transmigration. These processes are mediated by a sequence of interactions between the surface of leukocytes and endothelial cells, which require 


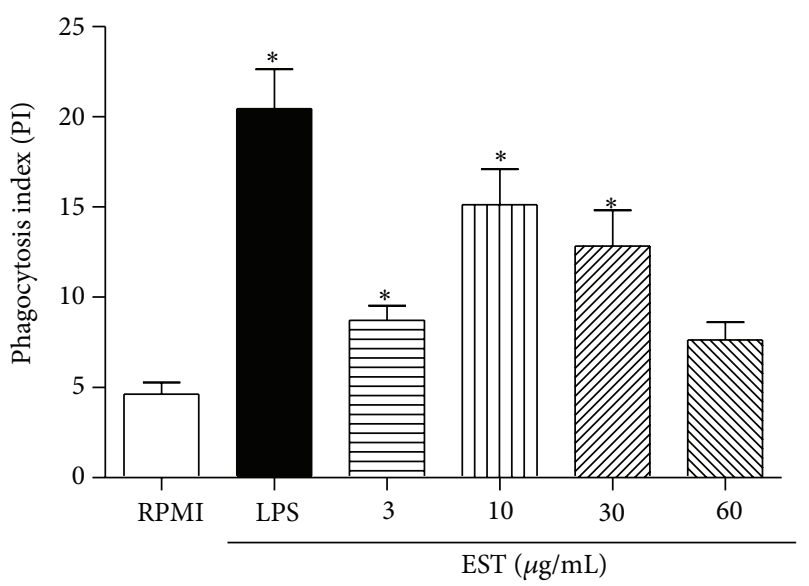

(a)

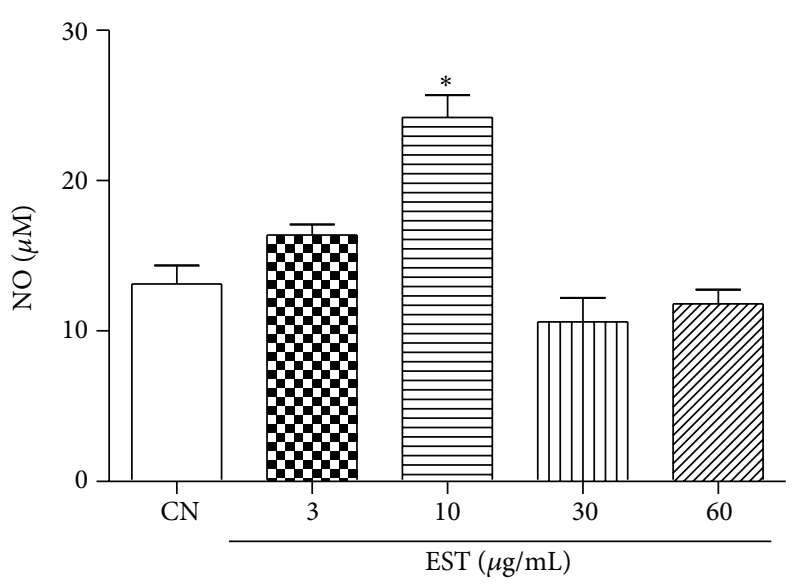

(b)

FIGURE 4: Effect of different concentrations of the EST on phagocytosis and NO production. (a) Phagocytosis index in macrophages. The peritoneal macrophages were incubated with $\operatorname{EST}(3,10,30$, and $60 \mu \mathrm{g} / \mathrm{mL})$ for 24 hours at $37^{\circ} \mathrm{C}$ with $5 \% \mathrm{CO}_{2}$. LPS $20 \mu \mathrm{g} / \mathrm{mL}$ was used as positive control. (b) NO production in peritoneal macrophages. Values represent mean \pm SEM $(n=5)$ and are representative of three independent experiments. ${ }^{*} P<0.05$ versus negative control (one-way ANOVA, Tukey's test).

the presence of a variety of adhesion molecules, chemokines, and cytokines (TNF- $\alpha$ and IL-1 $\beta$ ) [24-27]. Two hours after carrageenan injection $(100 \mu \mathrm{g} /$ cavity $)$ into the scrotum, a marked increase in the number of rolling and adherent leukocytes in the vascular endothelium was observed (Figures 3(a) and 3(b)). EST at all the doses tested $(250,500$, or $750 \mathrm{mg} / \mathrm{kg}$ ) caused a significant reduction of leukocytes rolling and this effect was more intense at the lower dose $(33,20 \%$; 16 , $92 \% ; 22,08 \%$, resp.). We also observed that the number of adherent leukocytes was reduced by EST at all doses tested. In addition, the leukocytes migration into the perivascular tissue was significantly diminished by EST in doses of 250 and $500 \mathrm{mg} / \mathrm{kg}$ (Figure 3(c)). A similar effect was also verified after treatment with reference drug, indomethacin $(5 \mathrm{mg} / \mathrm{kg})$.

Some studies have suggested that herbal compounds of the terpene group possess anti-inflammatory activity by inhibiting the production of TNF- $\alpha$ and IL-2 $[8,12,28,29]$. Recently it was demonstrated by our research group that anethole decreased the acute inflammatory process by inhibiting some mediators such as NO, PGE 2 , TNF, IL- $1 \beta$, and IL-17 and it was also able to inhibit leukocyte migration in vitro and in vivo $[7,9,23]$. Indeed, EST presented inhibitory activity on paw edema induced by TNF- $\alpha$ in mice [10]. Cytokines such as TNF and IL-1 $\beta$ promote leukocyte recruitment by inducing the integrins expression, the selectins expression on endothelial cells, and upregulation of ICAM expression [3032]. Considering the structural similarity between anethole and EST, and the effects already described to anethole on inflammatory response, it is possible that EST could be acting in the adhesion molecules production by inhibiting TNF and IL- $1 \beta$ production, with consequent reducing in the migration of leukocytes. However, it is necessary to perform additional experiments to evaluate the action of EST on the adhesion molecules.

Inflammation resolution begins in the first hours after the initiation of the inflammatory response and it is primarily mediated by resident macrophages recruited from the tissues. Macrophages represent the first line of defense against pathogens and constitute the largest group of phagocytic leukocytes, which have a crucial role in the immune response of inflammatory and infectious diseases and their actions involve phagocytic activities and secretion of proinflammatory mediators. When macrophages are stimulated, in vivo or in vitro, they respond with increased production of $\mathrm{NO}$ and hydrogen peroxide $\left(\mathrm{H}_{2} \mathrm{O}_{2}\right)$ that are highly toxic to microorganisms [33-35]. Since phagocytic activity is one of the most important functions of macrophages, the effect of EST on the phagocytic activity of macrophages was evaluated at concentrations of $3,10,30$, and $60 \mu \mathrm{g} / \mathrm{mL}$. Our results demonstrated that EST stimulated significantly the macrophages phagocytic ability in concentrations of 3,10 , and $30 \mu \mathrm{g} / \mathrm{mL}$, when compared with negative control group (Figure 4(a)). A similar effect was observed when LPS was used as positive control. LPS, a component of the membrane of Gram-negative bacteria, activates macrophages by binding the Toll-like receptors 4 (CD14/TLR4) complex, which promotes phagocytosis [36]. Thus, EST can also have stimulated the phagocytosis via binding with Toll-like receptors 4, but additional experiments are still necessary to confirm the mechanism.

Cytotoxicity assays in macrophages were done using same concentrations as described in the experiments above. EST at concentrations of $3,10,30$, and $60 \mu \mathrm{g} / \mathrm{mL}$ showed cell viability of $86 \%, 87 \%, 87 \%$, and $71 \%$, respectively. Only at a concentration of $60 \mu \mathrm{g} / \mathrm{mL}$ that EST did not stimulate the phagocytosis, probably due to the low cell viability (less than $75 \%)$.

$\mathrm{NO}$ is involved in several functions in the human body, such as blood pressure control, neurotransmission, and host defense [37]. Indeed, in the inflammation, NO participates in infection control, regulation of leukocyte rolling, migration, cytokine production, proliferation, and apoptosis [38]. It is 
well known that NO produced by macrophages is a cytotoxic molecule acting by a killing mechanism against invading microbes [35]. In the present work, different concentrations of EST $(3 \mu \mathrm{g} / \mathrm{mL}, 10 \mu \mathrm{g} / \mathrm{mL}, 30 \mu \mathrm{g} / \mathrm{mL}$, and $60 \mu \mathrm{g} / \mathrm{mL})$ on the production of NO were evaluated in the culture supernatant of peritoneal mice macrophages. As shown in Figure 4(b), the addition of EST significantly stimulated production of NO only at the concentration of $10 \mu \mathrm{g} / \mathrm{mL}$, similar to other natural products, such as Actin A, concanavalin A, and phytohemagglutinin $[36,39]$.

\section{Conclusion}

In conclusion, EST showed anti-inflammatory activity as demonstrated by the inhibition in the leukocyte recruitment and stimulation of phagocytic activity in macrophages. Thus, this compound may be a promising herbal medication in inflammatory process with excessive leukocyte migration. This finding is relevant since EST is a constituent of many essential oils used in aromatherapy and could be considered as nutraceutical. Further studies are needed to elucidate this possibility and also the anti-inflammatory mechanism of this drug.

\section{Conflict of Interests}

The authors declare that there is no conflict of interests regarding the publication of this paper.

\section{Acknowledgments}

The authors thank Jailson Araujo Dantas and Celia Regina Miranda for technical assistance. This study was supported by grants from the Coordenadoria de Aperfeiçoamento de Pessoal de Nível Superior (CAPES), Fundação Araucária, and Conselho Nacional de Desenvolvimento Científico e Tecnológico (CNPq), Brazil.

\section{References}

[1] M. de Vincenzi, M. Silano, F. Maialetti, and B. Scazzocchio, "Constituents of aromatic plants: II. Estragole," Fitoterapia, vol. 71, no. 6, pp. 725-729, 2000.

[2] J. G. M. Costa, F. F. G. Rodrigues, E. C. Angélico et al., "Composição química e avaliação da atividade antibacteriana e toxicidade do óleo essencial de Croton zehntneri (variedade estragol)," Revista Brasileira de Farmacognosia, vol. 18, no. 4, pp. 583-586, 2008.

[3] M. M. Bernardi, H. de Souza-Spinosa, M. J. M. Batatinha, and R. Giorgi, "Croton zehntneri: possible central nervous system effects in rodents," Journal of Ethnopharmacology, vol. 33, no. 3, pp. 285-287, 1991.

[4] J. H. Leal-Cardoso, B. G. Matos-Brito, J. E. G. Lopes-Junior et al., "Effects of estragole on the compound action potential of the rat sciatic nerve," Brazilian Journal of Medical and Biological Research, vol. 37, no. 8, pp. 1193-1198, 2004.

[5] A. A. Shahat, A. Y. Ibrahim, S. F. Hendawy et al., "Chemical composition, antimicrobial and antioxidant activities of essential oils from organically cultivated fennel cultivars," Molecules, vol. 16, no. 2, pp. 1366-1377, 2011.
[6] K. S. Silva-Alves, F. W. Ferreira-da-Silva, D. Peixoto-Neves et al., "Estragole blocks neuronal excitability by direct inhibition of $\mathrm{Na}+$ channels," Brazilian Journal of Medical and Biological Research, vol. 46, pp. 1056-1063, 2013.

[7] T. P. Domiciano, M. M. D. O. Dalalio, E. L. Silva et al., "Inhibitory effect of anethole in nonimmune acute inflammation," Naunyn-Schmiedeberg's Archives of Pharmacology, vol. 386, no. 4, pp. 331-338, 2013.

[8] G. B. N. Chainy, S. K. Manna, M. M. Chaturvedi, and B. B. Aggarwal, "Anethole blocks both early and late cellular responses transduced by tumor necrosis factor: effect on NF$\kappa \mathrm{B}, \mathrm{AP}-1, \mathrm{JNK}, \mathrm{MAPKK}$ and apoptosis," Oncogene, vol. 19, no. 25, pp. 2943-2950, 2000.

[9] A. M. V. Ritter, T. P. Domiciano, W. A. Verri Jr. et al., "Antihypernociceptive activity of anethole in experimental inflammatory pain," Inflammopharmacology, vol. 21, no. 2, pp. 187-197, 2013.

[10] E. L. Ponte, P. L. Sousa, M. V. A. P. Rocha et al., "Comparative study of the anti-edematogenic effects of anethole and estragole," Pharmacological Reports, vol. 64, no. 4, pp. 984-990, 2012.

[11] A. D. Luster, R. Alon, and U. H. von Andrian, "Immune cell migration in inflammation: present and future therapeutic targets," Nature Immunology, vol. 6, no. 12, pp. 1182-1190, 2005.

[12] B. de las Heras and S. Hortelano, "Molecular basis of the antiinflammatory effects of terpenoids," Inflammation \& AllergyDrug Targets, vol. 8, no. 1, pp. 28-39, 2009.

[13] E. R. Sherwood and T. Toliver-Kinsky, "Mechanisms of the inflammatory response," Best Practice and Research: Clinical Anaesthesiology, vol. 18, no. 3, pp. 385-405, 2004.

[14] F. Denizot and R. Lang, "Rapid colorimetric assay for cell growth and survival-modifications to the tetrazolium dye procedure giving improved sensitivity and reliability," Journal of Immunological Methods, vol. 89, no. 2, pp. 271-277, 1986.

[15] K. Ley, C. Laudanna, M. I. Cybulsky, and S. Nourshargh, "Getting to the site of inflammation: the leukocyte adhesion cascade updated," Nature Reviews Immunology, vol. 7, no. 9, pp. 678-689, 2007.

[16] D. D. Secco, J. A. Paron, S. H. P. De Oliveira, S. H. Ferreira, J. S. Silva, and F. D. Q. Cunha, "Neutrophil migration in inflammation: nitric oxide inhibits rolling, adhesion and induces apoptosis," Nitric Oxide, vol. 9, no. 3, pp. 153-164, 2003.

[17] E. J. B. Ramos, Y. Xu, I. Romanova et al., "Is obesity an inflammatory disease?" Surgery, vol. 134, no. 2, pp. 329-335, 2003.

[18] T. M. Cunha, W. A. Verri Jr., J. S. Silva, S. Poole, F. Q. Cunha, and S. H. Ferreira, "A cascade of cytokines mediates mechanical inflammatory hypernociception in mice," Proceedings of the National Academy of Sciences of the United States of America, vol. 102, no. 5, pp. 1755-1760, 2005.

[19] G. F. Passos, E. S. Fernandes, M. M. Campos et al., "Kinin B1 receptor up-regulation after lipopolysaccharide administration: role of proinflammatory cytokines and neutrophil influx," Journal of Immunology, vol. 172, no. 3, pp. 1839-1847, 2004.

[20] M. Iwata, S. Suzuki, Y. Asai, T. Inoue, and K. Takagi, "Involvement of nitric oxide in a rat model of carrageenin-induced pleurisy," Mediators of Inflammation, vol. 2010, Article ID 682879, 11 pages, 2010.

[21] J. R. G. D. S. Almeida, G. R. Souza, J. C. Silva et al., "Borneol, a bicyclic monoterpene alcohol, reduces nociceptive behavior and inflammatory response in Mice," The Scientific World Journal, vol. 2013, Article ID 808460, 5 pages, 2013.

[22] T. Fujita, K. H. Zawawi, H. Kurihara, and T. E. van Dyke, "CD38 cleavage in AMLP- and IL-8-induced chemotaxis is dependent 
on p38 MAP kinase but independent of p44/42 MAP kinase," Cellular Signalling, vol. 17, no. 2, pp. 167-175, 2005.

[23] C. F. Estevão-Silva, R. Kummer, F. C. Fachini-Queiroz et al., "Anethole and eugenol reduce in vitro and in vivo leukocyte migration induced by fMLP , $\mathrm{LTB}_{4}$, and carrageenan," Journal of Natural Medicines, vol. 68, no. 3, pp. 567-575, 2014.

[24] J. M. Cook-Mills and T. L. Deem, "Active participation of endothelial cells in inflammation," Journal of Leukocyte Biology, vol. 77, no. 4, pp. 487-495, 2005.

[25] W. A. Verri Jr., F. O. Souto, S. M. Vieira et al., "IL-33 induces neutrophil migration in rheumatoid arthritis and is a target of anti-TNF therapy," Annals of the Rheumatic Diseases, vol. 69, no. 9, pp. 1697-1703, 2010.

[26] S. M. Vieira, H. P. Lemos, R. Grespan et al., "A crucial role for TNF-alpha in mediating neutrophil influx induced by endogenously generated or exogenous chemokines, KC/CXCL1 and LIX/CXCL5," British Journal of Pharmacology, vol. 158, no. 3, pp. 779-789, 2009.

[27] P. H. Tsai, J. J. Liu, W. C. Chiu, M. H. Pai, and S. L. Yeh, "Effects of dietary glutamine on adhesion molecule expression and oxidative stress in mice with streptozotocin-induced type 1 diabetes," Clinical Nutrition, vol. 30, no. 1, pp. 124-129, 2011.

[28] A. Salminen, M. Lehtonen, T. Suuronen, K. Kaarniranta, and J. Huuskonen, "Terpenoids: natural inhibitors of NF- $\kappa$ B signaling with anti-inflammatory and anticancer potential," Cellular and Molecular Life Sciences, vol. 65, no. 19, pp. 2979-2999, 2008.

[29] S. S. Yea, H. Jeong, C. Y. Choi et al., "Inhibitory effect of anethole on T-lymphocyte proliferation and interleukin-2 production through down-regulation of the NF-AT and AP-1," Toxicology in Vitro, vol. 20, no. 7, pp. 1098-1105, 2006.

[30] W. A. Verri Jr., T. M. Cunha, S. H. Ferreira et al., "IL-15 mediates antigen-induced neutrophil migration by triggering IL-18 production," European Journal of Immunology, vol. 37, no. 12, pp. 3373-3380, 2007.

[31] E. Gaudreault, J. Stankova, and M. Rola-Pleszczynski, "Involvement of leukotriene B4 receptor 1 signaling in platelet-activating factor-mediated neutrophil degranulation and chemotaxis," Prostaglandins and Other Lipid Mediators, vol. 75, no. 1-4, pp. 25-34, 2005.

[32] J. G. Wagner and R. A. Roth, "Neutrophil migration mechanisms, with an emphasis on the pulmonary vasculature," Pharmacological Reviews, vol. 52, no. 3, pp. 349-374, 2000.

[33] V. N. Izgüt-Uysal, B. Gemici, and R. Tan, "Effect of orexin-A on phagocytic activity of peritoneal macrophage in starved rats," Cellular Immunology, vol. 271, no. 1, pp. 85-88, 2011.

[34] M. C. Kuo, C. Y. Chang, T. L. Cheng, and M. J. Wu, "Immunomodulatory effect of Antrodia camphorata mycelia and culture filtrate," Journal of Ethnopharmacology, vol. 120, no. 2, pp. 196-203, 2008.

[35] J. MacMicking, Q.-W. Xie, and C. Nathan, "Nitric oxide and macrophage function," Annual Review of Immunology, vol. 15, pp. 323-350, 1997.

[36] X. J. Zhang, Y. Li, G. X. Tai et al., "Effects of activin A on the activities of the mouse peritoneal macrophages," Cellular \& Molecular Immunology, vol. 2, no. 1, pp. 63-67, 2005.

[37] R. Korhonen, A. Lahti, H. Kankaanranta, and E. Moilanen, "Nitric oxide production and signaling in inflammation," Current Drug Targets: Inflammation \& Allergy, vol. 4, no. 4, pp. 471479, 2005.

[38] R. M. Clancy, A. R. Amin, and S. B. Abramson, "The role of nitric oxide in inflammation and immunity," Arthritis Rheumatoid, vol. 41, pp. 1141-1151, 1998.
[39] V. Kesherwani and A. Sodhi, "Differential activation of macrophages in vitro by lectin Concanavalin A, Phytohemagglutinin and Wheat germ agglutinin: production and regulation of nitric oxide," Nitric Oxide, vol. 16, no. 2, pp. 294-305, 2007. 


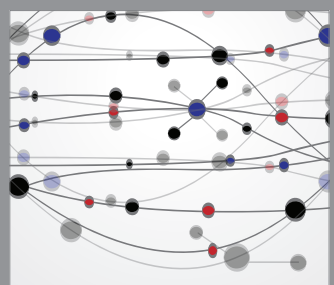

The Scientific World Journal
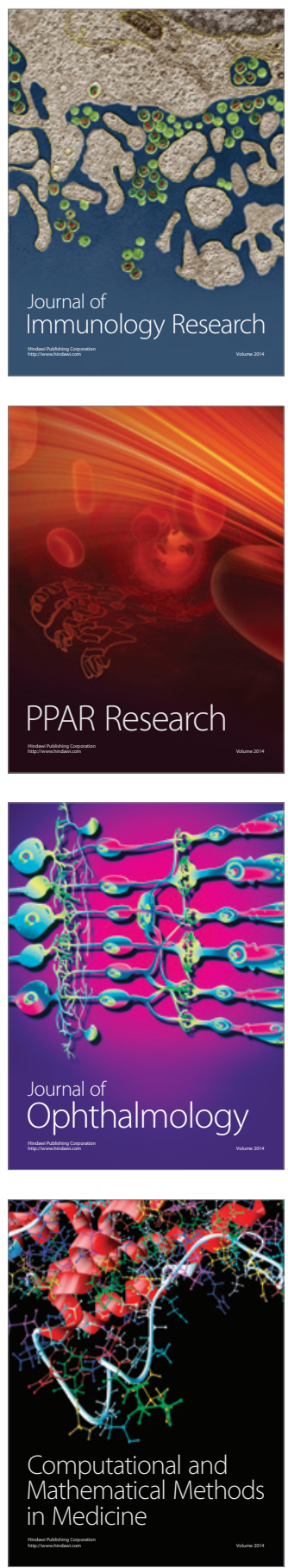

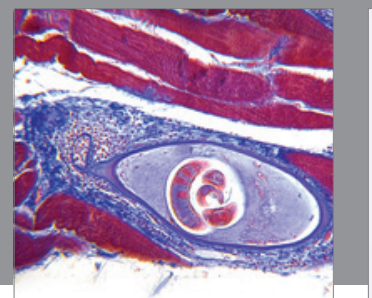

Gastroenterology

Research and Practice
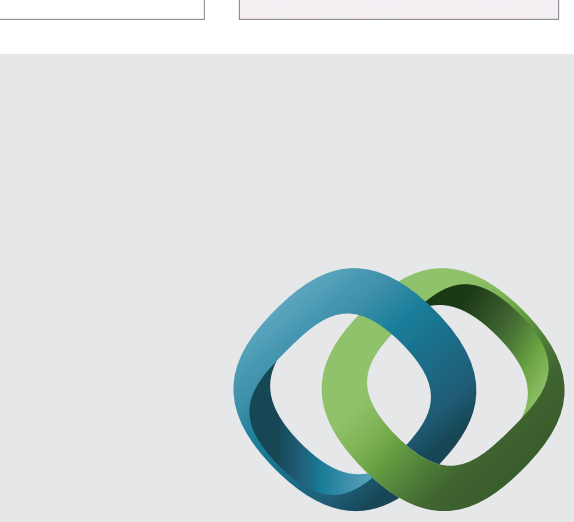

\section{Hindawi}

Submit your manuscripts at

http://www.hindawi.com
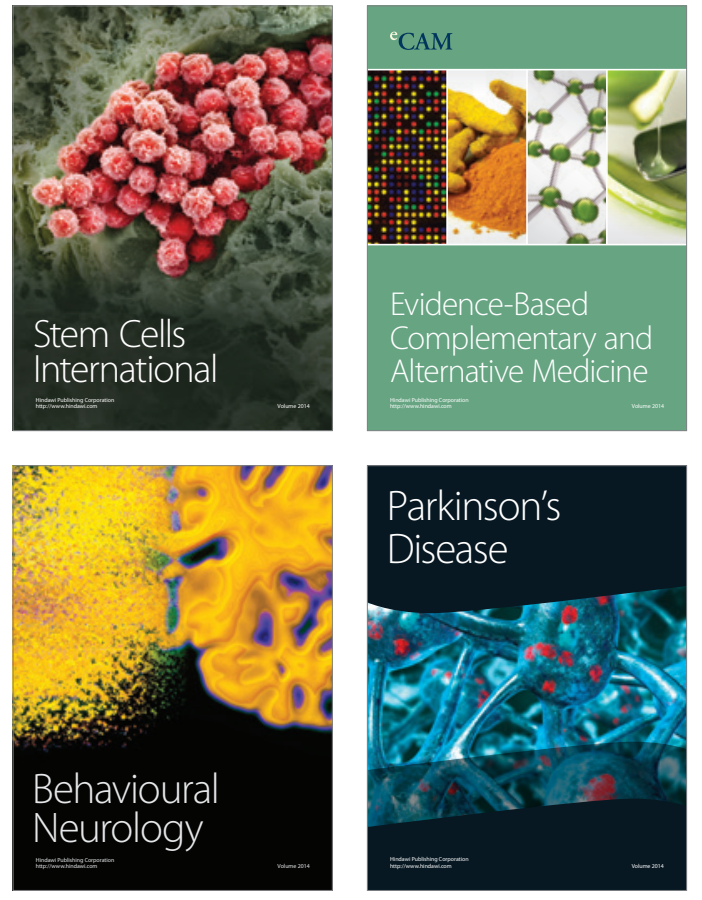
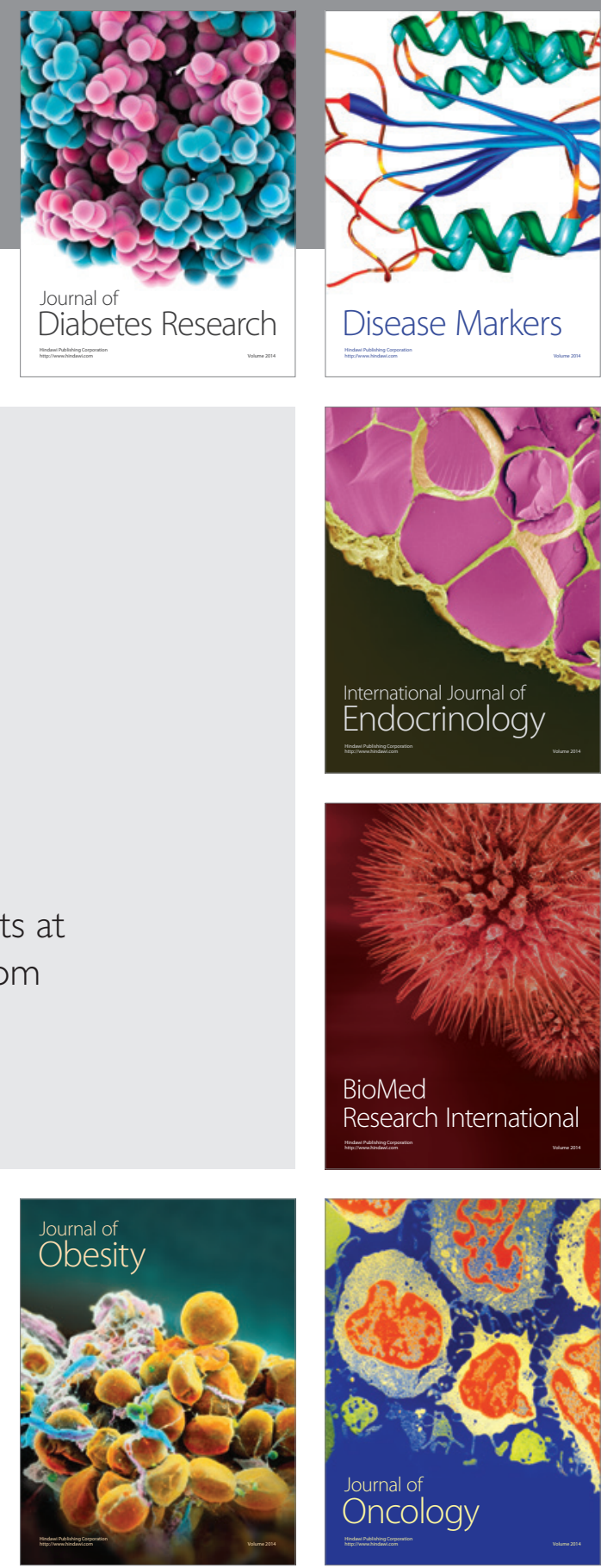

Disease Markers
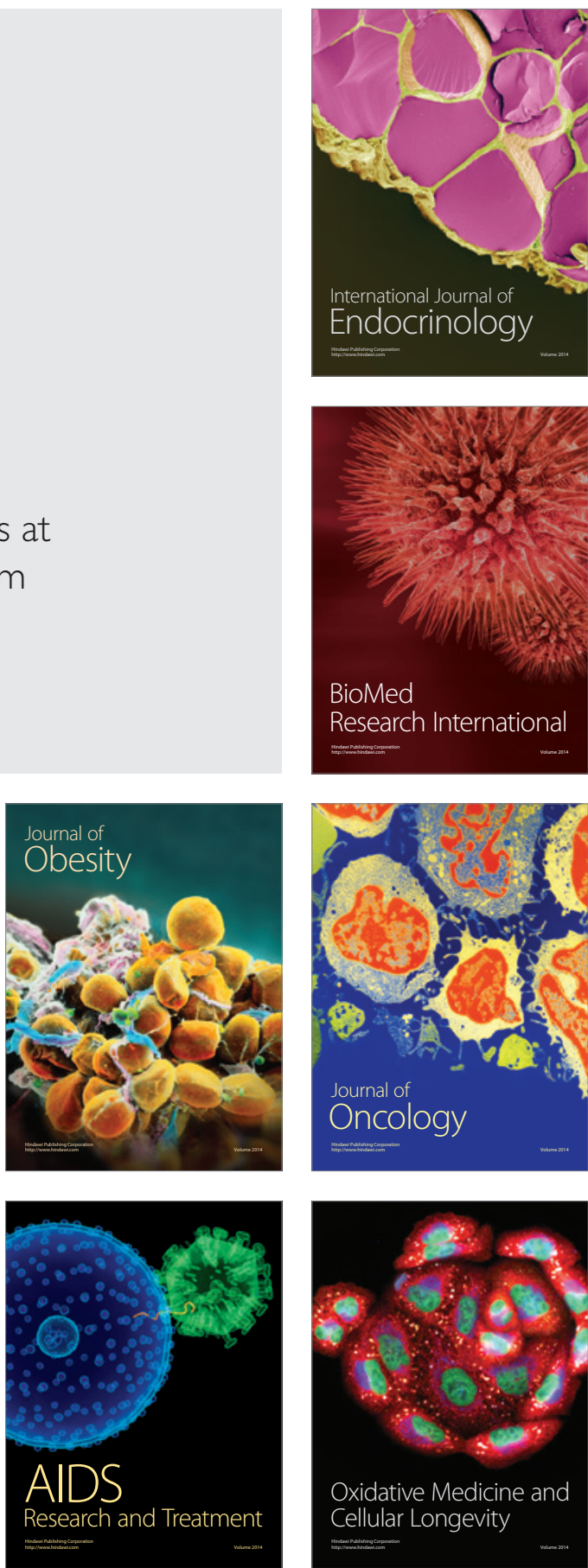